\title{
Cybridization of Grapefruit with 'Dancy' Mandarin Leads to Improved Fruit Characteristics
}

\author{
Aditi D. Satpute, Chunxian Chen', Fredrick G. Gmitter, Jr., Peng Ling, Qibin Yu, \\ Melinda R. Grosser ${ }^{2}$, and Jude W. Grosser ${ }^{3}$ \\ Citrus Research and Education Center, University of Florida/IFAS, 700 Experiment Station Road, \\ Lake Alfred, FL 33850 \\ Christine D. Chase \\ Horticultural Sciences Department, University of Florida/IFAS, 2215 Fifield Hall, Gainesville, FL \\ 32611
}

\begin{abstract}
AdDITIONAL INDEX WORDs. Citrus sinensis, Citrus paradisi, Citrus reticulata, protoplast fusion, cybrids, microsatellite marker
Abstract. In cybridization, new combinations of nuclear and cytoplasmic genes result in a unique genotype that may bring cellular, physical, physiological, and biochemical changes to the plant. This has been demonstrated in the unexpected cybrids generated from the fusion of citrus (Citrus sp.) protoplasts in two independent experiments. The first experiment was conducted to generate potentially seedless triploids by fusing diploid protoplasts of embryogenic 'Dancy' mandarin (Citrus reticulata) suspension culture cells with haploid 'Ruby Red' grapefruit $(C$. paradisi) protoplasts derived from tetrad-stage microspores. After multiple attempts, only one triploid was recovered, but several diploid plants with typical grapefruit morphology were also regenerated. In the second experiment, protoplasts derived from embryogenic 'Dancy' mandarin suspension culture were fused with nonembryogenic protoplasts from 'Duncan' grapefruit leaves in an effort to produce an allotetraploid somatic hybrid. The fruit from the resulting trees resembled grapefruit in morphology and type, and maintained excellent quality throughout the summer, when commercial grapefruit rapidly loses quality. Fruit on these trees remained firm with exceptional sweetness and good flavor into August, and without seed germination. The regenerants obtained in the protoplast fusion experiments were confirmed as cybrids by genetic marker analyses. The test grapefruit were identical to commercial 'Ruby Red' grapefruit at six nuclear simple sequence repeat (SSR) marker loci, but identical to 'Dancy' with respect to a mitochondrial intron marker. The plastid genomes of individual trees originated from either fusion partner. In the first experiment, haploid 'Ruby Red' protoplast preparations must have also contained contaminant diploid protoplasts. Apart from the value of altered fruit quality attributes in the marketplace, these plants provide an opportunity to understand the contributions of cytoplasmic organelle genetics to important citrus fruit-breeding objectives.
\end{abstract}

The genetic improvement of citrus is a challenge because of long generation times, polyembryony, and sexual incompatibilities (Grosser and Gmitter, 1990). To overcome these barriers, protoplast fusion and plant regeneration techniques have gained importance in citrus-breeding programs (Grosser and Gmitter, 2011; Grosser et al., 2000; Vardi et al., 1989). The novelty of somatic hybridization via protoplast fusion lies in the creation of new combinations of cytoplasm and nuclear genotypes (Grosser et al., 2000; Guo et al., 2013). Two types of outcomes are recovered from somatic cell fusions in which protoplasts isolated from the embryogenic callus/cell suspension are fused with the protoplasts derived from the nonembryogenic leaf mesophyll cells - somatic hybrids and cybrids (Grosser and Gmitter, 1990). Somatic hybrids contain a hybrid tetraploid nucleus, whereas cybrid cells retain the diploid nucleus from the nonembryogenic parent (Grosser et al., 2000; Guo et al., 2013). In citrus, diploid cybrids are often generated by interspecific fusion events (Cabasson et al., 2001; Moreira et al., 2000a;

Received for publication 4 Mar. 2015. Accepted for publication 1 July 2015. We thank the Krezdorn Memorial Fund, the Citrus Research and Development Foundation (CRDF), and New Varieties Development and Management Corporation (NVDMC) for financial support.

${ }^{1}$ Current address: USDA, ARS, SEFTNRL, 21 Dunbar Road, Byron, GA 31008 ${ }^{2}$ Current address: Department of Microbiology and Immunology, University of North Carolina, 116 Manning Drive, Chapel Hill, NC 27599

${ }^{3}$ Corresponding author. E-mail: jgrosser@ufl.edu.
Moriguchi et al., 1996), whereas tetraploid or amphidiploid somatic hybrids commonly result from intergeneric as well as interspecific combinations (Grosser and Gmitter, 2011; Grosser et al., 1992; Kobayashi et al., 1988, 1991; Louzada et al., 1992; Moriguchi et al., 1996; Ohgawara et al., 1985). These cell fusion outcomes also differ with respect to the cytoplasmic organelle (mitochondria and chloroplast) genotypes. In citrus, plants regenerated from protoplast fusion events almost always possess the mitochondrial DNA (mtDNA) of the embryogenic parent (Cabasson et al., 2001; Moriguchi et al., 1996; Saito et al., 1993; Yamamoto and Kobayashi, 1995), with some exceptions where restriction fragment length polymorphism markers revealed nonparental or recombinant mtDNA genotypes in somatic hybrids and cybrids (Moreira et al., 2000b; Moriguchi et al., 1997; Motomura et al., 1995; Vardi et al., 1989). These findings suggest that mitochondria of the embryogenic lines have a critical role in regeneration of cybrids and somatic hybrids (Grosser et al., 1996; Moriguchi et al., 1996; Saito et al., 1993; Yamamoto and Kobayashi, 1995). With respect to the chloroplast genotype of the regenerants, no specific pattern is seen. Either (Cabasson et al., 2001; Kobayashi et al., 1991; Moriguchi et al., 1996; Vardi et al., 1989) or both (Moreira et al., 2000b) of the fusion partner chloroplast DNAs (cpDNAs) are observed in cybrids as well as in the somatic hybrids. In summary, cybridization gives an opportunity to create novel, alloplasmic combinations of the nuclear and organelle genomes that are present in the fusion 
partners, whereas somatic hybridization produces hybrid nuclear genomes in combination with various patterns of organelle genotypes.

In citrus cybrids and somatic hybrids, plant morphology can be variable (Cabasson et al., 2001; Ohgawara et al., 1985). Moriguchi et al. (1996) reported that cybrids between 'Seminole' tangelo (Citrus reticulata $\times C$. paradisi $)+$ 'Lisbon' lemon $(C$. limon $)$ and between 'Hazzara' mandarin + rough lemon (C. jambhiri) have nonembryogenic parent 'Lisbon' or rough lemon leaf morphology, whereas somatic hybrids between 'Ohta' ponkan mandarin + rough lemon showed intermediate leaf morphology. Embryogenic parent morphology resembling sour orange (C. aurantium) or rough lemon is observed in cybrids generated by intergeneric fusion between sour orange or rough lemon + Microcitrus sp. (Vardi et al., 1989).

The different combinations of cytoplasmic and nuclear genomes in cybrids and somatic hybrids suggest the potential of protoplast fusion to create a wider range of unique germplasm resources for citrus improvement programs. Over the years, continuously evolving technology and the well-established protocol for cybridization have created interspecific as well as intergeneric cybrids and somatic hybrids in different citrusbreeding programs (Grosser and Gmitter, 2008, 2011; Grosser et al., 1988a, 1988b, 2000; Guo et al., 2013). Cybridization and somatic hybridization have addressed three main economically important objectives of citrus improvement: rootstock improvement (Grosser and Chandler, 2003; Grosser and Gmitter, 1990; Grosser et al., 2000) for disease resistance and soil adaptations, ploidy manipulation in the scion to create triploid seedless fruits or vigorous tetraploids (Grosser and Gmitter, 2008, 2011; Grosser et al., 2010a), and the creation of germplasm for interploid crosses between superior parental lines to avoid barriers of sexual incompatibility and cytoplasmic male/female sterility (Grosser and Gmitter, 2005). In this study, we confirmed new combinations of organelle and nuclear genomes created in two different protoplast fusion experiments: 'Dancy' mandarin + 'Ruby Red' grapefruit and 'Dancy' + 'Duncan' grapefruit produced by cybridization. This work associated novel nuclear-organelle genome combinations with desirable fruit traits promising new market opportunities for Florida citrus.

\section{Materials and Methods}

\section{Plant materials}

EXPLANTS FOR PROTOPLAST ISOLATION. The embryogenic suspension culture of 'Dancy' mandarin was started from unfertilized ovule-derived friable embryogenic callus cultures maintained in the citrus embryogenic callus collection of the University of Florida's Citrus Research and Education Center, Lake Alfred [UF-CREC (Grosser and Gmitter, 1990)]. Suspension-derived protoplasts were isolated from 1- to 2-yearold suspension cultures maintained in $\mathrm{H}+\mathrm{H}$ medium (Grosser and Gmitter, 1990) on a 2-week subculture cycle, with protoplasts isolated during days 4-12 (Grosser and Gmitter, 1990; Grosser et al., 2010b). Prepollen haploid protoplasts from 'Ruby Red' grapefruit were isolated as follows (Grosser and Gmitter, 1990): large elongated unopened flower buds were collected and meiotic stages were estimated by squashing anthers in water and examining the squashes using an inverted microscope at $\times 200$ magnification. The properly staged flower buds were decontaminated by immersing in $1 \mathrm{~N} \mathrm{HCl}$ for $30 \mathrm{~s}$ followed by $15 \mathrm{~min}$ immersion in $20 \%$ commercial bleach containing a few drops of a surfactant (Liquinox; Alconox, White Plains, $\mathrm{NY}$ ), then washed three times in double-distilled $\mathrm{H}_{2} \mathrm{O}$. Immature anthers were dissected from the buds and gently macerated into $2 \mathrm{~mL}$ BH3 medium (Grosser and Gmitter, 1990) in $60 \times 15-\mathrm{mm}$ petri dishes. To provide sterile explants for leaf protoplast isolation, fruit of 'Duncan' grapefruit were washed thoroughly and surface disinfected in $1.5 \%$ sodium hypochlorite for $30 \mathrm{~min}$, followed by a rinse in sterile water. Then fruit was sprayed with $95 \%$ ethanol. Fruit were cut with a sharp knife at the equatorial zone, avoiding the core where seeds are embedded. Fruit were twisted with each half in opposite directions until separated to allow for removal of intact seeds. Seeds were germinated and seedlings were maintained in Magenta vessels (GA-7; Magenta Corp., Chicago, IL) containing $50 \mathrm{~mL}$ RMA medium (Grosser and Gmitter, 1990; Grosser et al., 2010b) and wrapped with a sealing film (Nescofilm ${ }^{\circledR}$; Bando Chemical Industries, Kobe, Japan). Tender, expanded leaves from the cultured nucellar seedlings were used for protoplast isolation. Shoots of the seedlings were subcultured as needed to provide a continuous source of sterile leaves.

Protoplast isolation And fusion. Protoplasts were isolated from the parental suspension cultures in a 2.5:1.5 (v:v) mixture of $0.7 \mathrm{M} \mathrm{BH} 3$ protoplast culture medium and enzyme solution as described previously (Grosser and Gmitter, 1990; Grosser et al., 2010 b). Sterile leaves from in vitro cultured nucellar seedlings were feather-cut with a sharp scalpel, and macerated anthers were incubated overnight (including a 25-min vacuum infiltration) in an $8: 3(\mathrm{v}: \mathrm{v})$ mixture of $0.6 \mathrm{M} \mathrm{BH} 3$ protoplast culture medium and modified enzyme solution. Protoplasts from both suspension and leaf sources were purified by passing through a $45-\mu \mathrm{m}$ stainless-steel mesh screen and then by centrifuging on $25 \%$ sucrose and 13\% mannitol gradient. Haploid protoplasts are not amenable to purification on a sucrose-mannitol gradient, but were washed in $25 \%$ sucrose containing citrus protoplast wash (Grosser and Gmitter, 1990) nutrients to facilitate removal of debris before fusion.

In the first group of experiments, embryogenic suspension culture-derived protoplasts of 'Dancy' mandarin were fused with the tetrad-derived haploid protoplasts from 'Ruby Red' grapefruit (Fig. 1). In the second group of experiments, our highly successful model method of fusing embryogenic suspension culture-derived protoplasts of one parent with leafderived protoplasts of the second parent was used (Grosser and Gmitter, 1990; Grosser et al., 2000). Fusions were conducted in $60 \times 15-\mathrm{mm}$ polystyrene petri dishes using our standard $40 \%$ polyethylene glycol volumetric plating method (Grosser and Gmitter, 1990). Following fusion, protoplasts were cultured in a $1: 1(\mathrm{v}: \mathrm{v})$ mixture of $0.6 \mathrm{M} \mathrm{BH} 3$ and $0.6 \mathrm{M}$ EME protoplast culture media (Grosser and Gmitter, 1990), and petri dishes sealed with Nescofilm ${ }^{\circledR}$ were maintained in plastic boxes under low light in a tissue culture room.

Plant Regeneration and Ploidy analysis. Regenerating embryogenic calli and embryoids were transferred to solid EME medium containing $0.5 \mathrm{~g} \cdot \mathrm{L}^{-1}$ malt extract (Perez et al., 1998) for somatic embryo induction according to Grosser and Gmitter (1990). After 4 weeks, embryos were cultured for one passage on EME-1500 media containing $1.5 \mathrm{~g} \cdot \mathrm{L}^{-1}$ malt extract for embryo enlargement, followed by one or two passages on $\mathrm{B}+$ embryo germination medium (Grosser and Gmitter, 1990). Large embryos that failed to germinate, often exhibiting abnormal shapes, were sliced horizontally with a sharp scalpel and transferred directly to DBA3 (Deng et al., 1992) medium for adventitious 


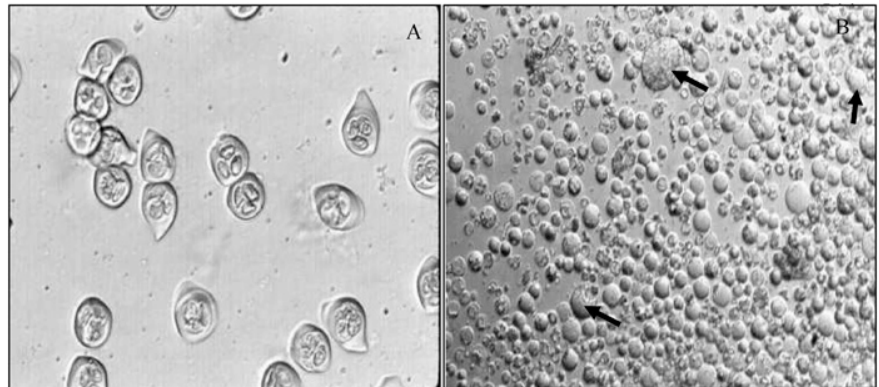

Fig. 1. 'Ruby Red' grapefruit microspore preparation for protoplast fusion. (A) Tetrad microspores before enzyme treatment observed under $\times 200$ magnification, (B) microspore protoplasts after enzyme digestion. Arrows show the putative contaminant diploid cells.

shoot induction. Recovered adventitious shoots and shoots from germinated embryos with poor root systems were cut and rooted on RMAN (Grosser and Gmitter, 1990) medium in Magenta boxes. Germinated embryos with good roots were also transferred to RMAN for plantlet enlargement. Recovered rooted plantlets were screened for ploidy level using a tabletop flow cytometer (Partec, Münster, Germany), as previously described (Khan and Grosser, 2004). Numerous fruit-bearing trees, each from an independent regeneration event and with typical grapefruit morphology, grafted to 'Swingle' citrumelo (C. paradisi $\times$ Poncirus trifoliata) rootstock, were recovered from each group of experiments and were planted (1989) in the North-40 grove at UF-CREC.

DNA EXtraction. Plant leaf materials used for DNA extraction were collected from the experimental scions, control 'Ruby Red', 'Marsh' and 'Duncan' grapefruit, and 'Dancy' mandarin trees located at UF-CREC. All experimental scions were 25 years old and grafted onto 'Swingle' citrumelo rootstock. 'Dancy' mandarin and 'Marsh' grapefruit DNAs were used in the initial screening procedure to identify chloroplast primer pairs that revealed polymorphism between mandarin and grapefruit polymerase chain reaction (PCR) amplicons.

\section{Plant genotyping}

Regenerants recovered from the 'Dancy' + 'Ruby Red' experiments (C1, C2, C3, G3, G4, and G7) and 'Dancy' + 'Duncan' experiments (G1, G2, G5, and G6) were selected for genotyping (Table 1). Total genomic DNA was extracted from the experimental scions, 'Ruby Red', 'Duncan' and 'Marsh' grapefruit, and 'Dancy' mandarin using GeneElute ${ }^{\mathrm{TM}}$ plant genomic DNA Miniprep kit (Sigma-Aldrich, St. Louis, MO). Extracted DNA was quantified using a spectrophotometer (Smartspec $^{\mathrm{TM}}$; Bio-Rad Laboratories, Hercules, CA), and dilutions were made to the concentration of $10 \mathrm{ng} \cdot \mu \mathrm{L}^{-1}$ in $0.1 \mathrm{X}$ NTE buffer [ $1 \mathrm{~mm}$ Trizma base, $0.1 \mathrm{~mm}$ ethylenediaminetetraacetic acid (EDTA), $0.001 \mathrm{M} \mathrm{NaCl}$. For nuclear genotyping, six expressed sequence tag, simple sequence repeat (EST-SSR) primers, CX6F04B, CX6F18G, CX6F29Y, CX0010B, CX0035G, and CX2021R, along with the genotyping procedure, were previously described (Chen et al., 2006, 2008). Fluorescently labeled PCR products produced on DNA templates prepared from regenerants and parental controls were fractionated on a genetic analyzer (3130 xL; Applied Biosystems, Foster City, CA). The alleles of each EST-SSR were scored from the files with a marker analysis software (GeneMarker ${ }^{\circledR}$; SoftGenetics, State College, PA).
The PCR primers used for organelle genotyping are described in Table 1. Forward and reverse primers flanking the mitochondrial NADH dehydrogenase subunit 7 intron 1 (nad7i1) (Grosser, 2011) were used for mitochondrial genotyping. For chloroplast genotyping, the 23 primer pairs developed for amplification of monocot cpDNA (Tsuruta et al., 2008) were tested to identify those that amplified citrus DNA and revealed polymorphism between the fusion partners. PCR reactions contained $10 \mathrm{ng} \cdot \mu_{\mathrm{L}^{-1}}$ of genomic DNA and of the master-mix. For mitochondrial markers, $23 \mu \mathrm{L}$ of master-mix contained $2 \mu \mathrm{M}$ forward and reverse primer stock each (SigmaAldrich), $2.5 \mathrm{~mm}$ dNTP mix, 10X Ex Taq ${ }^{\circledR}$ Hot-Start reaction buffer (TaKaRa Bio, Otsu, Japan), 5 units/ $\mu \mathrm{L}$ of TaKaRa Ex $\mathrm{Taq}^{\circledR}$ DNA Polymerase Hot-Start Version and sterile distilled water. For chloroplast markers, the PCR mixture contained $2 \mu \mathrm{M}$ forward and reverse primer each, $2 \mathrm{X} \mathrm{GoTaq}{ }^{\circledR}$ Hot Start Colorless Master Mix (Promega Corp., Madison, WI) and target DNA template $\left(10 \mathrm{ng} \cdot \mu \mathrm{L}^{-1}\right)$. Amplification of the target DNA was achieved in a programmable thermocycler (Bio-Rad Laboratories). PCR amplification was 30 cycles of denaturation at $94{ }^{\circ} \mathrm{C}$ for $1 \mathrm{~min}$, followed by annealing at $55^{\circ} \mathrm{C}$ for $2 \mathrm{~min}$ and extension at $72{ }^{\circ} \mathrm{C}$ for $3 \mathrm{~min}$.

PCR amplification was first confirmed by electrophoresis through a $1 \%$ agarose gel. For mitochondrial markers, $5 \mu \mathrm{L}$ of PCR product, $5 \mu \mathrm{L}$ of distilled water, and $3 \mu \mathrm{L}$ of $5 \mathrm{X}$ loading dye (Bioline, Taunton, MA) was loaded into each agarose gel lane. For chloroplast markers, $5 \mu \mathrm{L}$ of PCR product and $2 \mu \mathrm{L}$ of loading dye were loaded in each lane. The DNA Hyperladder II TM $^{\mathrm{TM}}$ (Bioline) was used to estimate amplicon size. Gels were run in $1 \mathrm{X}$ Tris-Borate-EDTA (TBE) buffer $(0.1 \mathrm{M}$ Trizma base, $0.1 \mathrm{M}$ boric acid, and $0.0025 \mathrm{M} \mathrm{Na}_{2}$ EDTA at $\mathrm{pH} 8.2$ ) for $45 \mathrm{~min}$ at $90 \mathrm{~V}$ for chloroplast and $60 \mathrm{~V}$ for mitochondrial PCR products. Gels were stained in ethidium bromide $\left(1 \mu \mathrm{g} \cdot \mathrm{mL}^{-1}\right)$ solution for $15 \mathrm{~min}$ and visualized over an ultraviolet transilluminator (Bio-Rad Laboratories). Successful PCR reactions were also fractionated on $10 \%$ precast polyacrylamide gel (Criterion $^{\mathrm{TM}}$, Bio-Rad Laboratories) to determine whether polymorphisms were present between fusion partners 'Dancy' mandarin and 'Ruby Red' or 'Duncan' grapefruit. Acrylamide gel samples of $2 \mu \mathrm{L}$ contained $0.5 \mu \mathrm{L}$ PCR-amplified DNA, $0.5 \mu \mathrm{L}$ water, and $1 \mu \mathrm{L} 6 \mathrm{X}$ orange-blue loading dye (Promega Corp.). The G210A 100-bp DNA ladder (Promega Corp.) was used to estimate amplicon size. Acrylamide gels were run at $90 \mathrm{~V}$ for $4 \mathrm{~h}$ in $1 \mathrm{X}$ TBE buffer. Gels were stained in ethidium bromide (1 $\mu \mathrm{g} \cdot \mathrm{mL}^{-1}$ ) for $15 \mathrm{~min}$ and visualized over an ultraviolet transilluminator. Confirmation of the mitochondria or chloroplast polymorphisms among the fusion partners and experimental scions was obtained by electrophoresis of mixed PCR products; 'Dancy' with experimental scion, 'Ruby Red' with experimental scion, and 'Dancy' with 'Ruby Red'. Mixed samples were diluted in distilled water in the proportion of 1:1 to decrease the band intensity and observe the clear separation between the mixed amplicons in the same gel lane.

\section{Fruit quality traits}

In each experiment, a total of 25 fruits were harvested from experimental scions at three different time points, pooled together to analyze juice quality and yield. The Florida Department of Agriculture and Consumer Services approved juice extractor (JBT Corp., Chicago IL) and automated brix-acid unit system was used to determine fruit quality parameters - soluble solid content, total acid content, juice weight, and fruit weight. 
Table 1. Citrus parents used in the protoplast fusion experiments.

\begin{tabular}{lcc}
\hline & \multicolumn{2}{c}{ Fusion parental genotype } \\
\cline { 2 - 3 } identification no. & $\begin{array}{c}\text { Embryogenic } \\
\text { parent }^{z}\end{array}$ & $\begin{array}{c}\text { Nonembryogenic } \\
\text { parent }\end{array}$ \\
\hline C1 & Dancy & Ruby Red \\
C2 & Dancy & Ruby Red \\
C3 & Dancy & Ruby Red \\
G3 & Dancy & Ruby Red \\
G4 & Dancy & Ruby Red \\
G7 & Dancy & Ruby Red \\
G1 & Dancy & Duncan \\
G2 & Dancy & Duncan \\
G5 & Dancy & Duncan \\
G6 & Dancy & Duncan \\
\hline
\end{tabular}

'Protoplast derived from cell suspension culture of 'Dancy' mandarin. y Prepollen haploid protoplasts isolated from all 'Ruby Red' grapefruit fusion parents.

${ }^{x}$ Leaf mesophyll cells used to obtain protoplast from all 'Duncan' grapefruit fusion parents.

\section{Results and Discussion}

GENETIC CHARACTERIZATION OF SCIONS RECOVERED FROM 'DANCY' + 'RuBY RED' AND 'DANCY' + 'DUNCAN' FUSION EXPERIMENTS. On the basis of six EST-SSR markers used to test the nuclear genomic composition of the experimental scions, all regenerants in both the 'Dancy' + 'Ruby Red' and 'Dancy' + 'Duncan' protoplast fusion experiments carried the allelic composition of grapefruit nuclear DNA. The allelic combinations of 'Dancy' mandarin were different from those of the experimental scions (Table 2).

Of the 23 monocot chloroplast primer pairs tested for PCR amplification of 'Dancy' and 'Marsh' DNA, six amplified both 'Marsh' and 'Dancy' templates, whereas two amplified 'Marsh' grapefruit DNA only. The six primers that amplified both citrus templates targeted intergenic and intron regions and the $n d h k$ genic region of the cpDNA (Table 3 ). Two of these six markers produced amplicons that revealed polymorphism between 'Dancy' and 'Marsh' DNA. These primers targeted the trnD$p s b M$ intergenic region and $n d h k$ region of the plastid genome (Table 3 ). These two markers were also polymorphic between
'Dancy' and 'Ruby Red' grapefruit when PCR products were fractionated on a $10 \%$ acrylamide gel (not shown). The mixture of $n d h k$ PCR products from 'Dancy' and 'Ruby Red' or 'Duncan' showed better separation than the mixture of the trnD-psbM intergenic region PCR products. Therefore, the $n d h k$ marker was used to determine the chloroplast genotype of the cybrids (Fig. 2).

PCR products amplified with the plastid ndhk primer pair revealed no polymorphism between cybrids $\mathrm{C} 1, \mathrm{C} 2, \mathrm{C} 3, \mathrm{G} 3$, G4, and G7 and the 'Dancy' fusion partner (Fig. 3A and B), but well-separated bands were observed when the PCR amplicon of 'Ruby Red' was mixed with that of C1, C2, C3, G3, G4, or G7 (Fig. 3A and C). PCR products amplified from the cybrids $\mathrm{G} 2$ and G6 revealed no polymorphism when mixed with the 'Dancy' PCR product. However, mixed PCR products from G1 with 'Dancy' and from G5 with 'Dancy' showed a separation of bands on the acrylamide gel (Fig. 3B). Well-separated bands were observed when the PCR amplicon of 'Ruby Red' was mixed with that of G2 or G6, but not when the 'Ruby Red' amplicon was mixed with that of the G1 or G5 amplicons (Fig. 3C). Therefore, the grapefruit cybrids G2 and G6 carried the 'Dancy' chloroplast genotype, whereas G1 and G5 carried the grapefruit chloroplast genotype.

The mitochondrial nad7il primer pair amplified the 'Marsh', 'Ruby Red', 'Dancy', and putative cybrid DNAs as observed on a $1 \%$ agarose gel, but did not reveal a clear polymorphism (not shown). Polymorphism was, however, observed in the mixture of PCR products amplified from 'Dancy' mandarin and from 'Ruby Red', 'Duncan', and 'Marsh' grapefruit DNA when these products were fractionated on a $10 \%$ acrylamide gel (Fig. 2). In the 'Dancy' + 'Ruby Red' protoplast fusion experiment, polymorphism was observed in the mixture of $\mathrm{PCR}$ product from each of the experimental scions C1, C2, C3, G3, G4, and G7 with the 'Ruby Red' amplicon (Fig. 4A and C), while band separation was not observed when each scion PCR product was mixed with the 'Dancy' amplicon (Fig. 4A and B). Therefore, all of the experimental scions were confirmed to be cybrids carrying the 'Dancy' mitotype in combination with the grapefruit nuclear genotype.

The mitochondrial nad7il primer pair was also used to identify the mitotype of each regenerant (G1, G2, G5, and G6) created by the protoplast fusion of 'Dancy' + 'Duncan'.

Table 2. Organelle and nuclear genotypes of experimental citrus cybrids.

\begin{tabular}{|c|c|c|c|c|c|c|c|c|}
\hline \multirow[b]{2}{*}{ Sample } & \multirow[b]{2}{*}{$n d h k(\mathrm{bp})^{\mathrm{x}}$} & \multirow[b]{2}{*}{ nad7i1 (bp) } & \multicolumn{6}{|c|}{ EST-SSR markers $(b p)^{z}$} \\
\hline & & & $\mathrm{CX} 0010 \mathrm{~B}$ & CX0035G & CX2021R & CX6F04B & CX6F18G & CX6F29Y \\
\hline Ruby Red & 650 & 1300 & $217 / 229$ & $182 /-$ & $150 / 152$ & $162 / 174$ & $154 / 160$ & $151 / 154$ \\
\hline Dancy & 550 & 1225 & $220.2 / 229$ & $173 /-$ & $148 / 150$ & $150 / 162$ & $154 /-$ & $151 /-$ \\
\hline $\mathrm{C} 2$ & 550 & 1225 & $217 / 229$ & $182 /-$ & $150 / 152$ & $162 / 174$ & $154 / 160$ & $151 / 154$ \\
\hline $\mathrm{C} 3$ & 550 & 1225 & $217 / 229$ & $182 /-$ & $150 / 152$ & $162 / 174$ & $154 / 160$ & $151 / 154$ \\
\hline G3 & 550 & 1225 & $217 / 229$ & $182 /-$ & $150 / 152$ & $162 / 174$ & $154 / 160$ & $151 / 154$ \\
\hline G7 & 550 & 1225 & $217 / 229$ & $182 /-$ & $150 / 152$ & $162 / 174$ & $154 / 160$ & $151 / 154$ \\
\hline G1 & 650 & 1225 & $217 / 229$ & $182 /-$ & $150 / 152$ & $162 / 174$ & $154 / 160$ & $151 / 154$ \\
\hline G2 & 550 & 1225 & $217 / 229$ & $182 /-$ & $150 / 152$ & $162 / 174$ & $154 / 160$ & $151 / 154$ \\
\hline G5 & 650 & 1225 & $217 / 229$ & $182 /-$ & $150 / 152$ & $162 / 174$ & $154 / 160$ & $151 / 154$ \\
\hline G6 & 550 & 1225 & $217 / 229$ & $182 /-$ & $150 / 152$ & $162 / 174$ & $154 / 160$ & $151 / 154$ \\
\hline
\end{tabular}

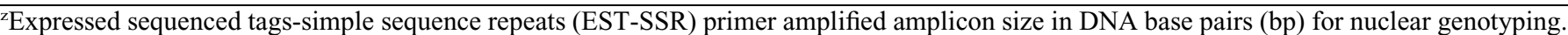
${ }^{y}$ Amplicon size of nad7il mitochondrial primer pair amplified PCR product expressed in the bp.

${ }^{\mathrm{x}}$ Amplicon size of $n d h k$ plastid primer pair amplified PCR product expressed in the bp. 


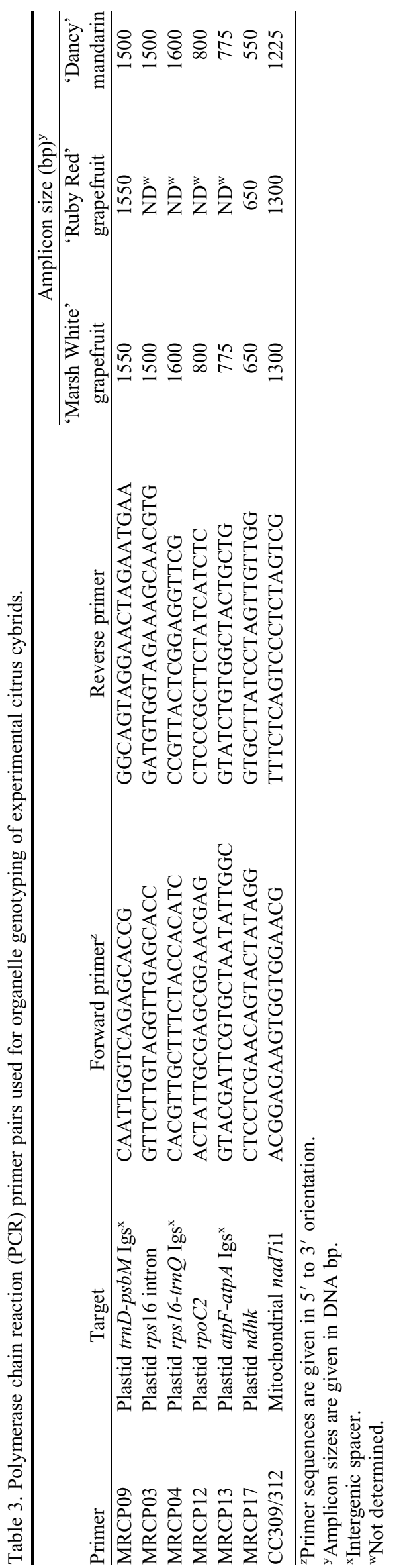

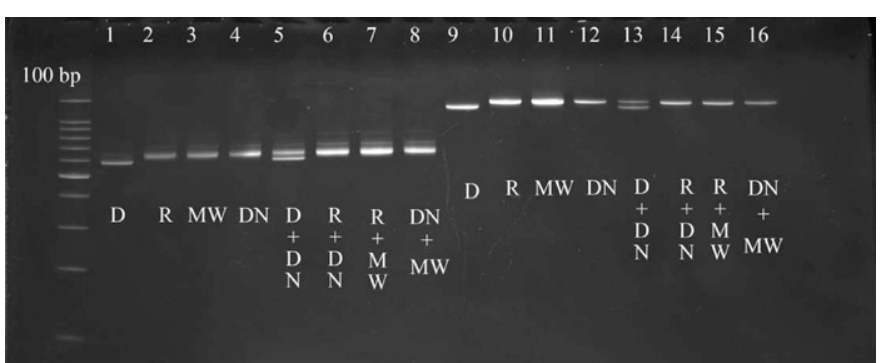

Fig. 2. Electrophoretic separation of plastid and mitochondrial polymerase chain reaction (PCR) amplicons from grapefruit and mandarin fusion parents and products. Lanes 1-8 contain $n d h k$ plastid amplicons and 9-10 contain nad7il mitochondrial amplicons. PCR products from different fusion parents were fractionated individually and in combination to confirm monomorphic or polymorphic amplicon sizes. 100-bp DNA ladder; D = 'Dancy' mandarin amplicon; R = 'Ruby Red' grapefruit amplicon; MW = 'Marsh' grapefruit amplicon; $\mathrm{DN}=$ 'Duncan' grapefruit amplicon.

Polymorphism was observed in the mixture of PCR-amplified DNA of regenerants and 'Ruby Red' amplicon on $10 \%$ acrylamide gel (Fig. 4C). However, this separation was not observed when PCR-amplified G1, G2, G5, and G6 DNAs were mixed with 'Dancy' PCR-amplified product (Fig. 4B). The regenerants of fusion experiment 'Dancy' + 'Duncan' were, therefore, also cybrids carrying 'Dancy' mitochondrial genotype in combination with the grapefruit nuclear genotype.

\section{Plant phenotypes}

Cybrids generated in both fusion experiments had fruit type and leaf morphology similar to their respective nonembryogenic parents (Fig. 5A-C). Fruit obtained in the 'Dancy' + 'Ruby Red' fusion events contained very few seeds, characteristic of the 'Ruby Red' fusion parent. Fruit obtained from 'Dancy' + 'Duncan' fusion events were seedy, similar to that of the 'Duncan' fusion parent. In contrast to the wild-type 'Duncan' seeds, those of the cybrids did not germinate as the fruit aged on the tree (Fig. 5A and B). Examination of 10 fruit each from the cybrid 'Duncan' and original wild-type Duncan cultivar in late July (2014) revealed that nearly every seed in the original 'Duncan' had germinated, whereas it was difficult to find a germinated seed in the cybrid 'Duncan'. Vivipary was also almost completely absent in the 'Ruby Red' cybrids.

\section{Fruit quality and yield traits}

Fruit and juice quality data (Table 4) were obtained at three different time points for each of the parental and cybrid selections, and for one additional commercial grapefruit cultivar-Thompson. Juice weight calculated as a percent of fruit weight showed that juice contributed greater than $50 \%$ of fruit weight in all but one sample. The soluble solids concentration and soluble solids concentration/acid ratios were always consistently higher in the cybrid fruits. In fact, some individual cybrid fruit exhibited soluble solids concentration levels higher than $13 \%$. This increase was consistent in late summer also (Table 4). The soluble solids concentration/acid ratio is an important juice quality determinant, and fruits obtained in the fusion experiments showed a high ratio at all three time points compared with commercial grapefruit cultivars-Thompson, Duncan, and Ruby Red.

\section{Discussion}

The citrus scions regenerated from the fusion of protoplasts in two different experiments (embryogenic 'Dancy' 

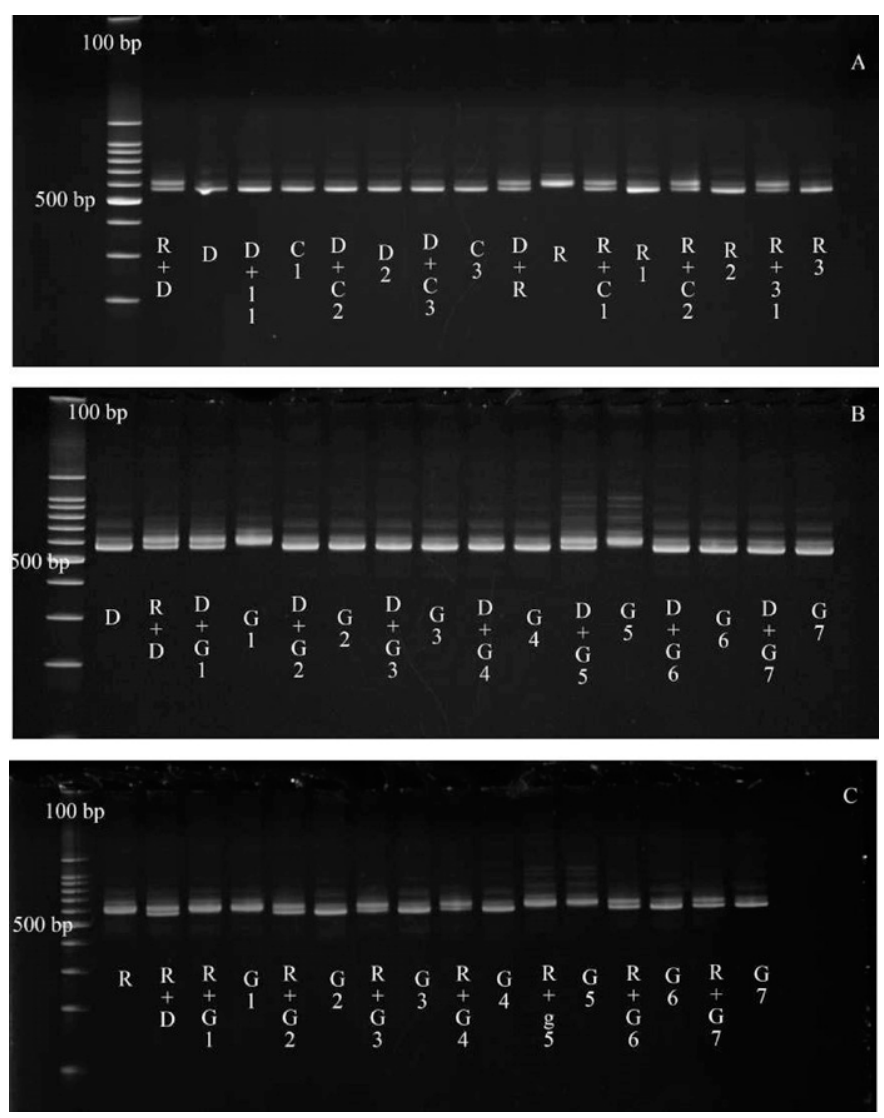

Fig. 3. Electrophoretic separation of plastid $n d h k$ PCR amplicons from grapefruit and mandarin fusion parents and products. PCR products from experimental scions and fusion parents were fractionated individually or in combination to confirm monomorphic or polymorphic amplicons sizes. (A) Mixtures of polymerase chain reaction (PCR) amplicons from experimental scion C1-C3 + 'Dancy' mandarin or 'Ruby Red' grapefruit amplicons, (B) mixtures of PCR amplicons from experimental scion G1-G7 with 'Dancy' mandarin amplicon, (C) mixture of PCR amplicons from experimental scion G1-G7 with 'Ruby Red' grapefruit amplicon. 100-bp DNA ladder; D = 'Dancy' mandarin amplicon; $\mathrm{R}=$ 'Ruby Red' grapefruit amplicon.

callus + tetrad 'Ruby Red' microspore and embryogenic 'Dancy' callus + nonembryogenic 'Duncan' leaf) resembled grapefruit in leaf morphology and fruit type. Furthermore, nuclear genotyping of all recovered putative cybrids matched that of diploid grapefruit for all six loci tested. These observations were surprising in the case of the 'Dancy' + 'Ruby Red' experiment. These scions were expected to be triploids carrying the diploid genome of the 'Dancy' fusion partner and one haploid genome from the 'Ruby Red' microspore. Contamination of the 'Ruby Red' haploid microspores with diploid 'Ruby Red' microspore mother or surrounding anther cells (Fig. 1B) is the likely explanation for this outcome. A doubled genome contribution from haploid 'Ruby Red' microspores is ruled out by the heterozygosity of the experimental scions at six nuclear microsatellite markers (Table 3). Grosser et al. (1996) have discussed the requirements for cybridization and the probable reasons that one of the parental nuclei degenerates to result in a cybrid as opposed to a somatic hybrid. It is also possible that imbalanced or asynchronous conditions during cell division lead to inheritance of only one of the parental nuclei into cybrids (Guo et al., 2013).
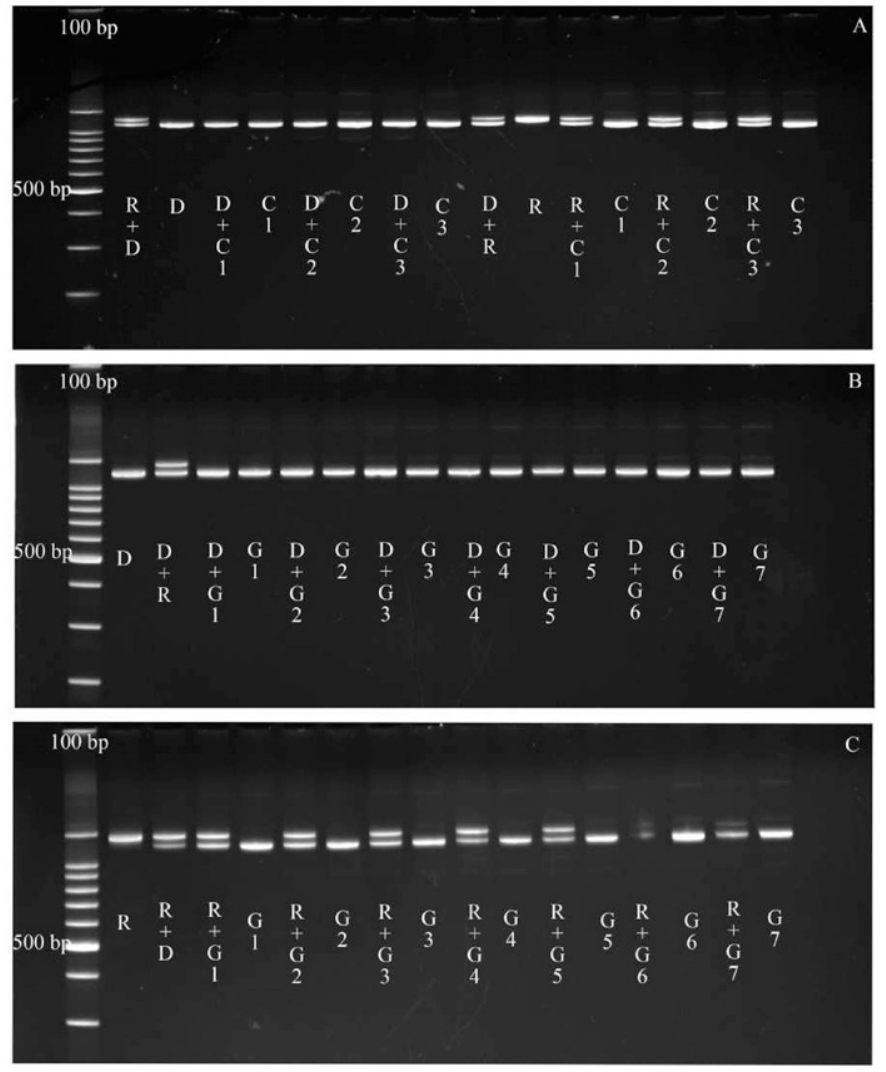

Fig. 4. Electrophoretic separation of mitochondrial nad7i1 PCR amplicons from grapefruit and mandarin fusion parents and products. Polymerase chain reaction (PCR) products from experimental scions and fusion parents were fractionated individually or in combination to confirm monomorphic or polymorphic amplicon sizes. (A) Mixtures of PCR amplicons from experimental scion C1-C3 + 'Dancy' mandarin or 'Ruby Red' grapefruit amplicons, (B) mixtures of PCR amplicons from experimental scion G1-G7 with 'Dancy' mandarin amplicon, (C) mixture of experimental scion G1-G7 with 'Ruby Red' grapefruit amplicon. 100-bp DNA ladder; D = 'Dancy' mandarin amplicon; R = 'Ruby Red' grapefruit amplicon.

PCR assays for the analysis of mitotype showed all 10 of the experimental scions to be cybrids carrying the mitochondrial marker from the embryogenic callus fusion partner 'Dancy' combined with the nuclear markers derived from the nonembryogenic grapefruit fusion partner. In the absence of fully sequenced genomes, some nuclear genome contribution from 'Dancy' or mitochondrial genome contribution from grapefruit cannot be excluded. Plant mitochondrial genomes are relatively large and exhibit a complex organization due to active recombination (Gualberto et al., 2014; Maréchal and Brisson, 2010). This, along with the capability for mitochondrial fusion (Logan, 2010), generates the opportunity for creation of chimeric (recombinant) or multiple (heteroplasmic) mitochondrial genotypes during somatic cell fusion events. Nevertheless, our findings are consistent with the previous studies yielding citrus cybrids (Moreira et al., 2000a; Moriguchi et al., 1996; Saito et al., 1993; Yamamoto and Kobayashi, 1995). The mechanism for the biased inheritance of the mitochondrial markers from the embryogenic callus parent of the cybridization event is still unknown. There are different hypotheses proposed. Bonnema et al. (1992) interpreted the results of organelle and nuclear inheritance in the cybrids created between tomato (Solanum lycopersicum) and Solanum penellii 


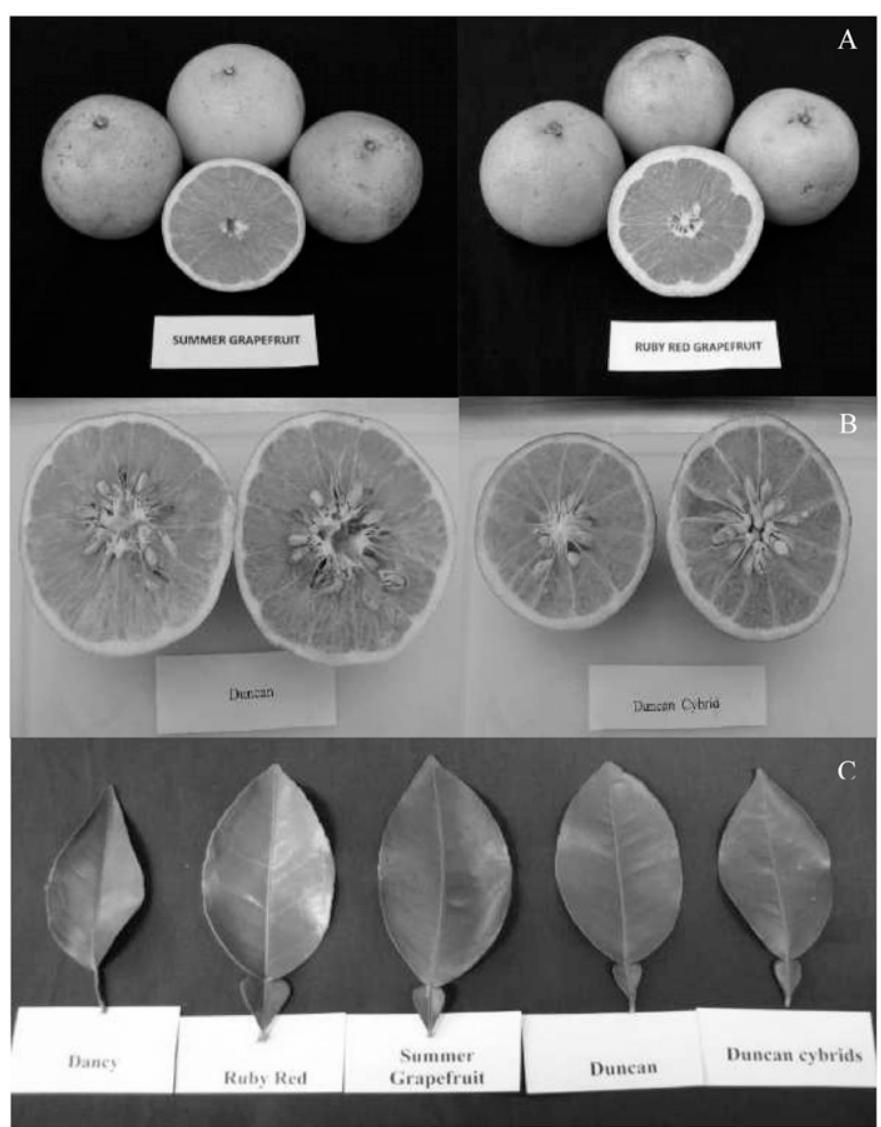

Fig. 5. Fruit and leaf phenotypes of cybrids and fusion parents. (A) Summer Grapefruit (cybrid) and 'Ruby Red' grapefruit (control), (B) 'Duncan' grapefruit control showing germinated seeds within the fruit and 'Duncan' cybrid showing the absence of seed germination (July), (C) leaf morphology of cybrids and fusion parents.

as the inheritance of the organelles influenced by the nuclear background in the cybrids, whereas Earle (1995) proposed that it is spontaneous, culture-related changes rather than the effect of the fusion event. The amount of mtDNA in embryogenic cells culture is about four times more compared with nonembryogenic mesophyll cells (Moreira et al., 2000a), but this difference seems an unlikely basis for consistent transmission of the embryogenic cell mitotype. Biased partitioning of mitochondria following cell fusion might be explained by the status of mitochondria in dedifferentiated as compared with dedifferentiating cells. Massive mitochondrial fusion is observed in dedifferentiating protoplasts of tobacco (Nicotiana tabacum) mesophyll cells, whereas protoplasts of fully dedifferentiated suspension and callus cultures have numerous, small, uniformly distributed mitochondria (Sheahan et al., 2005). Hence, the physical distribution of mitochondria in the dedifferentiated embryogenic callus of 'Dancy' might promote the inheritance of 'Dancy' mitochondria to the cybrids. A critical role of mitochondria from the embryogenic callus parent in somatic embryogenesis is supported by the observation that unfused mesophyll protoplasts are unable to divide in absence of embryogenic suspension protoplasts (Moriguchi et al., 1996).

Cybrids C1, C2, C3, G2, G3, G4, G6, and G7 carried the chloroplast marker from the embryogenic callus 'Dancy', whereas cybrids G1 and G5 carried the marker from the nonembryogenic grapefruit fusion partner. Thus, the 'Dancy' + 'Ruby Red' fusion resulted in transmission of only the 'Dancy' cpDNA, whereas the 'Dancy' + 'Duncan' fusion led to transmission of the cpDNA from either parent. Additional regenerants should be investigated to determine whether there was a true bias in cpDNA transmission in the former experiment. Such a bias might result from the nature of the plastids in the unknown, diploid 'Ruby Red' fusion cell, as compared with the 'Duncan' leaf protoplast cell. Inheritance of cpDNA from either fusion partner was expected based upon past studies of cybridization (Grosser et al., 1996; Moreira et al., 2000a). In addition to the effect of alloplasmy, heteroplasmy present within cytoplasmic organelles is also suspected to bring desirable or undesirable nonparental changes in the regenerants. The expression of nonparental traits because of heteroplasmy was observed to be quantitative and documented in both plant and animal kingdom (Picard et al., 2014; Szklarczyk et al., 2014). In this study, the absence of information of mitochondrial and chloroplast genome suggests the possibility of the presence of quantitative distribution of heteroplasmic mitochondrial and chloroplast DNA sequences and its role in improving the traits in the cybrids.

New combinations of nuclear and cytoplasmic genes are predicted to bring changes to the cellular, physical, physiological, and biochemical aspects of the tree. Rootstock development, ploidy manipulation, and generation of elite germplasm for the conventional breeding are breeding goals of cybridization (Grosser and Gmitter, 2005, 2011). To date, few cybridization experiments have created economically viable cultivars, but the new cybrids created between 'Dancy' and grapefruit-derived protoplasts have a market potential due to attributes of fruit quality lasting well past the current harvest season. The high sugar and low acidity, combined with optimum juice content, demonstrate the potential of these newly created cybrids to stand out in competition with commercial grapefruit in the Florida juice industry and international fruit market. This finding was

Table 4. Comparison between commercial citrus cultivars and cybrid fruit for amount of juice, concentration of soluble solids and the total acid level (data from Florida Department of Agriculture and Consumer Services approved test facility).

\begin{tabular}{|c|c|c|c|c|c|c|c|c|c|c|c|c|c|c|c|}
\hline & \multicolumn{3}{|c|}{ Thompson grapefruit } & \multicolumn{3}{|c|}{ Ruby Red grapefruit } & \multicolumn{3}{|c|}{ Duncan grapefruit } & \multicolumn{3}{|c|}{ Ruby Red cybrid } & \multicolumn{3}{|c|}{ 'Duncan' cybrid } \\
\hline December & 58 & 9.93 & 1.21 & 57 & 9.33 & 1.32 & 62 & 8.52 & 1.28 & 56 & 11.64 & 1.44 & 45 & 10.87 & 1.38 \\
\hline June & 64 & 10.36 & 1.18 & 67 & 9.51 & 1.08 & 51 & 9.42 & 1.23 & 52 & 11.67 & 1.19 & 54 & 14.05 & 1.03 \\
\hline
\end{tabular}

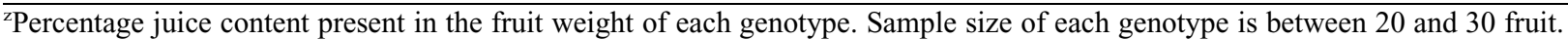

${ }^{y}$ Measures the percentage of concentration of total soluble solids in the fruit juice of experimental cybrids and commercial grapefruit cultivars. ${ }^{x}$ Measures percentage of total acids present in the juice.

$\mathrm{JC}=$ juice content; $\mathrm{SS}=$ soluble solids; $\mathrm{AC}=$ acid content. 
unexpected based on the results of Bassene et al. (2008), who showed that in 'Eureka' lemon cybrids carrying the 'Willowleaf' mandarin mitochondria, fruit quality traits, including sugar content, largely matched those of the nuclear genome donor. One clone from this work, cybrid 'Ruby Red' C2 has already been released by UF for commercialization under the proposed name 'Summer Gold Grapefruit'. This clone has the potential to extend the grapefruit packing season, and high concentration of soluble solids grapefruit brings higher prices in several international markets. A cybrid 'Duncan' clone will be released subsequently for dooryard use. (The high seed content precludes commercial use.)

Further research is required to understand and predict the contributions of cytoplasmic organelle genetics to important breeding traits. It was recently shown that nuclear gene expression is changed after acquiring foreign mitochondria from 'Willowleaf' mandarin under nuclear background of 'Eureka' lemon in the cybrids created by fusion between embryogenic 'Willowleaf' mandarin and nonembryogenic 'Eureka' lemon (Bassene et al., 2011). The transcriptome and proteome analysis conducted to quantify the differential expression between cybrids and its fusion partners also suggests the modulation of mitochondrial genes under the effect of foreign nuclear genotype or vice versa (Wang et al., 2010; Zheng et al., 2012). The cybrid fruit traits observed in the fusion between 'Dancy' + 'Ruby Red' and 'Dancy' + 'Duncan' will provide another approach toward understanding nuclear and cytoplasmic interaction in the control of advantageous plant phenotypes.

\section{Literature Cited}

Bassene, J.-B., L. Berti, E. Carcouet, C. Dhuique-Mayer, A.-L. Fanciullino, J. Bouffin, P. Ollitrault, and Y. Froelicher. 2008. Influence of mitochondria origin on fruit quality in a citrus cybrid. J. Agr. Food Chem. 56:8635-8640.

Bassene, J.B., Y. Froelicher, L. Navarro, P. Ollitrault, and G. Ancillo. 2011. Influence of mitochondria on gene expression in citrus cybrid. Plant Cell Rpt. 30:1077-1085.

Bonnema, A.B., J.M. Melzer, L.W. Murray, and M.A. O'Connell. 1992. Non-random inheritance of organellar genome in symmetric and asymmetric somatic hybrids between Lycopersicon esculentum and L. pennellii. Theor. Appl. Genet. 84:435-442.

Cabasson, C.M., F. Luro, P. Ollitrault, and J.W. Grosser. 2001. Nonrandom inheritance of mitochondrial genomes in citrus hybrids produced by protoplast fusion. Plant Cell Rpt. 20:604-609.

Chen, C., K. Bowman, Y. Choi, P. Dang, M. Rao, S. Huang, J. Soneji, T. McCollum, and F. Gmitter, Jr. 2008. EST-SSR genetic maps for Citrus sinensis and Poncirus trifoliata. Tree Genet. Genomes 4:1-10.

Chen, C., P. Zhou, Y. Choi, S. Huang, and F. Gmitter, Jr. 2006. Mining and characterizing microsatellites from citrus ESTs. Theor. Appl. Genet. 112:1248-1257.

Deng, X.X., J.W. Grosser, and F.G. Gmitter, Jr. 1992. Intergeneric somatic hybrid plants from protoplast fusion of Fortunella crassifolia cultivar 'Meiwa' with Citrus sinensis cultivar 'Valencia'. Sci. Hort. 49:55-62.

Earle, E.D. 1995. Mitochondrial DNA in somatic hybrids and cybrids, p. 557-584. In: C. Levings, III and I. Vasil (eds.). Advances in cellular and molecular biology of plants. Kluwer Academic Publ., Dordrecht, The Netherlands.

Grosser, J.W. and J.L. Chandler. 2003. New rootstock development via protoplast fusion. Acta Hort. 622:491-497.

Grosser, J.W. and F.G. Gmitter, Jr. 1990. Protoplast fusion and citrus improvement. Plant Breed. Rev. 8:339-374.

Grosser, J.W. and F.G. Gmitter, Jr. 2005. 2004 SIVB Congress symposium proceedings thinking outside the cell-applications of somatic hybridization and cybridization in crop improvement with citrus as a model. In Vitro Cell. Dev. Biol. Plant 41:220-225.
Grosser, J.W. and F.G. Gmitter, Jr. 2008. In vitro breeding provides new and unique opportunity for conventional breeding. Acta Hort. 829:65-72.

Grosser, J.W. and F.G. Gmitter, Jr. 2011. Protoplast fusion for production of tetraploid and application for scion and rootstock breeding in citrus. Plant Cell Tissue Organ Cult. 104:343-357.

Grosser, J.W., F.G. Gmitter, Jr., and J.L. Chandler. 1988a. Intergeneric somatic hybrid plants of Citrus sinensis cv. Hamlin and Poncirus trifoliata cv. Flying Dragon. Plant Cell Rpt. 7:5-8.

Grosser, J.W., F.G. Gmitter, Jr., and J.L. Chandler. 1988b. Intergeneric somatic hybrid plants from sexually incompatible woody species. Citrus sinensis and Severinia disticha. Theor. Appl. Genet. 75:397-401.

Grosser, J.W., F.G. Gmitter, Jr., E.S. Louzada, and J.L. Chandler. 1992. Production of somatic hybrid and autotetraploid breeding parents for seedless citrus development. HortScience 27:1125-1127. Grosser, J.W., F.G. Gmitter, Jr., N. Tusa, G.R. Recupero, and P. Cucinotta. 1996. Further evidence of a cybridization requirement for plant regeneration from citrus leaf protoplast following somatic fusion. Plant Cell Rpt. 15:672-676.

Grosser, J.W., H.J. An, M. Calovic, D. Lee, C. Chen, M. Vasconcellos, and F.G. Gmitter, Jr. 2010a. Production of new allotetraploid and autotetraploid citrus breeding parents: Focus on zipperskin mandarins. HortScience 45:1-4.

Grosser, J.W., M. Calovic, and E.S. Louzada. 2010b. Protoplast fusion technology-Somatic hybridization and cybridization, p. 175-198. In: M.R. Davey and P. Anthony (eds.). Plant cell culture. Wiley, Chichester, UK.

Grosser, J.W., P. Ollitrault, and O. Olivares-Fuster. 2000. Somatic hybridization in citrus: An effective tool to facilitate variety improvement. In Vitro Cell. Dev. Biol. Plant 36:434-449.

Grosser, M. 2011. Plant Mitochondrial Introns as Genetic Markers. 6 May 2015. <http://www.honors.ufl.edu/apps/Thesis.aspx/ Download/898>.

Gualberto, J.M., D. Mileshina, C. Wallt, A.K. Niazi, F. Weber-Lotfi, and A. Dietrich. 2014. The plant mitochondrial genome: Dynamics and maintenance. Biochimie 100:107-120.

Guo, W.W., S.X. Xiao, and X.X. Deng. 2013. Somatic cybrid production via protoplast fusion for citrus improvement. Sci. Hort. 163:20-26.

Khan, I.A. and J.W. Grosser. 2004. Regeneration and characterization of somatic hybrid plants of Citrus sinensis (sweet orange) and Citrus micrantha, a progenitor species of lime. Euphytica 137:271-278.

Kobayashi, S., T. Ohgawara, K. Fujiwara, and I. Oiyama. 1991. Analysis of cytoplasmic genome in somatic hybrid between navel orange (Citrus sinensis Osb.) and 'Murcott tangor'. Theor. Appl. Genet. 82:6-10.

Kobayashi, S., T. Ohgawara, S. Ohgawara, I. Oiyama, and S. Ishii. 1988. A somatic hybrid plant obtained by protoplast fusion between navel orange (Citrus sinensis) and satsuma mandarin (C. unshiu). Plant Cell Tissue Organ Cult. 14:63-69.

Logan, D.C. 2010. The dynamic plant chondriome. Semin. Cell Dev. Biol. 21:550-557.

Louzada, E.S., J.W. Grosser, F.G. Gmitter, Jr., B. Neilsen, and J.L. Chandler. 1992. Eight new somatic hybrid citrus rootstocks with potential for improved disease resistance. HortScience 27:10331036.

Maréchal, A. and N. Brisson. 2010. Recombination and the maintenance of plant organelle genome stability. New Phytol. 186:299-317.

Moreira, C.D., C.D. Chase, F.G. Gmitter, Jr., and J.W. Grosser. 2000a. Inheritance of organelle genome in citrus somatic cybrids. Mol. Breed. 6:401-405.

Moreira, C.D., C.D. Chase, F.G. Gmitter, Jr., and J.W. Grosser. 2000 b. Transmission of organelle genome in citrus somatic hybrids. Plant Cell Tissue Organ Cult. 61:165-168.

Moriguchi, T., T. Hidaka, and M. Omura. 1996. Genotype and parental combination influence efficiency of cybrids induction in citrus by electrofusion. HortScience 31:275-278. 
Moriguchi, T., T. Motomura, T. Hidaka, T. Akihama, and M. Omura. 1997. Analysis of mitochondrial genomes among citrus plants produced by the interspecific somatic fusion of 'Seminole' tangelo with rough lemon. Plant Cell Rpt. 16:397-400.

Motomura, T., T. Hidaka, T. Moriguchi, T. Akihama, and M. Omura. 1995. Intergeneric somatic hybrids between Citrus and Atalantia or Severinia by electrofusion, and recombination of mitochondrial genomes. Breed. Sci. 45:309-314.

Ohgawara, T., S. Kobayashi, E. Ohgawara, H. Uchimiya, and S. Ishii. 1985. Somatic hybrid plants obtained by protoplast fusion between Citrus sinensis and Poncirus trifoliata. Theor. Appl. Genet. 71:1-4.

Perez, R.M., A.M. Galiana, L. Navarro, and N. Duran-Vila. 1998. Embryogenesis in vitro of several Citrus species and cultivars. J. Hort. Sci. Biotechnol. 73:796-802.

Picard, M., J. Zhang, S. Hancock, O. Derbeneva, R. Golhar, P. Golik, S. O’Hearn, S. Levy, P. Potluri, M. Lvova, A. Davila, C.S. Lin, J.C. Perin, E.F. Rappaport, H. Hakonarson, I.A. Trounce, V. Procaccio, and D.C. Wallace. 2014. Progressive increase in mtDNA 3243A $>$ G heteroplasmy causes abrupt transcriptional reprogramming. Proc. Natl. Acad. Sci. USA 111:4033-4042.

Saito, W., T. Ohgawara, J. Shimizu, S. Ishii, and S. Kobayashi. 1993. Citrus cybrids generation following cell fusion between nucellar cells and mesophyll cells. Plant Sci. 88:195-201.

Sheahan, M., D. McCurdy, and R. Rose. 2005. Mitochondria as a connected population: Ensuring continuity of the mitochondrial genome during plant cell dedifferentiated through massive mitochondrial fusion. Plant J. 44:744-755.

Szklarczyk, M., M. Szymański, M. Wójcik-Jagła, P.W. Simon, A. Weihe, and T. Börner. 2014. Mitochondrial atp9 genes from petaloid male-sterile and male-fertile carrots differ in their status of heteroplasmy, recombination involvement, post-transcriptional processing as well as accumulation of RNA and protein product. Theor. Appl. Genet. 127:1689-1701.

Tsuruta, S., F. Hosaka, T. Otabara, M. Hashiguchi, T. Yamamoto, and R. Akashi. 2008. Genetic diversity of chloroplast DNA in Zoysia and other warm-season turfgrasses. Grassland Sci. 54:151-159.

Vardi, A., P. Arzee-Gonen, A. Frydman-Shani, S. Bleichman, and E. Galun. 1989. Protoplast-fusion-mediated transfer of organelles from Microcitrus into citrus and regeneration of novel alloplasmic trees. Theor. Appl. Genet. 78:741-747.

Yamamoto, M. and S. Kobayashi. 1995. A cybrid plant produced by electrofusion between Citrus unshiu (satsuma mandarin) and $C$. sinensis (sweet orange). Plant Tissue Cult. Lett. 12:131-137.

Wang, L., Z.Y. Pan, and W.W. Guo. 2010. Proteomic analysis of leaves from a diploid cybrid produced by protoplast fusion between satsuma mandarin and pummelo. Plant Cell Tissue Organ Cult. 103:165-174. Zheng, B.B., X.M. Wu, X.X. Ge, X.X. Deng, J.W. Grosser, and W.W. Guo. 2012. Comparative transcript profiling of a male sterile cybrid pummelo and its fertile type revealed altered gene expression related to flower development. PLoS One 7:1-13. 